\title{
Relationship between glyco-oxidation, antioxidant status and microalbuminuria in type 2 diabetic patients
}

\author{
F. Piarulli • G. Sartore • A. Ceriello • E. Ragazzi • \\ R. Reitano $\cdot$ L. Nollino $\cdot$ C. Cosma $\cdot$ D. Fedele • \\ A. Lapolla
}

Received: 30 December 2008 / Accepted: 8 March 2009 / Published online: 29 April 2009

(C) Springer-Verlag 2009

\begin{abstract}
Aims/hypothesis This study examined the relationship, if any, between glucose-induced oxidative stress, antioxidant status and microalbuminuria in patients with type 2 diabetes.

Methods The study involved 99 consecutive type 2 diabetic patients (57 men, 42 women). Patients with persistent microalbuminuria were identified and the following variables evaluated: fasting plasma glucose, $\mathrm{HbA}_{1 \mathrm{c}}$, malonyldialdehyde (MDA), pentosidine, AGE, the total radical-trapping antioxidant parameter (TRAP), vitamin E, creatinine, estimated GFR and lipid profile.

Results Patients were divided into two groups, i.e. 37 individuals without microalbuminuria (AER $<20 \mu \mathrm{g} / \mathrm{min}$ ) and 62 with microalbuminuria (AER $\geq 20 \mu \mathrm{g} / \mathrm{min}$ ). The following variables were significantly higher in patients with microalbuminuria than in those without microalbuminuria (mean $\pm \mathrm{SD}$ ): fasting plasma glucose $9.41 \pm 2.88$ vs $8.19 \pm 1.93 \mathrm{mmol} / \mathrm{l}, p<0.05 ; \mathrm{HbA}_{1 \mathrm{c}} 7.97 \pm 1.51$ vs $7.39 \pm$ $1.03 \%, p<0.05$; MDA $1.18 \pm 0.35$ vs $1.02 \pm 0.29 \mu \mathrm{mol} / 1, p<$
\end{abstract}

F. Piarulli $(\bowtie) \cdot$ G. Sartore $\cdot$ R. Reitano $\cdot$ L. Nollino $\cdot$ C. Cosma •

D. Fedele $\cdot$ A. Lapolla

Department of Medical and Surgical Sciences,

University of Padova,

Via dei Colli 4,

35143 Padova, Italy

e-mail: francesco.piarulli@unipd.it
0.05 ; pentosidine $98.5 \pm 24.6$ vs $82.9 \pm 20.9 \mathrm{pmol} / \mathrm{ml}, p<$ 0.005 ; and AGE $13.2 \pm 4.8$ vs $10.6 \pm 3.8 \mu \mathrm{g} / \mathrm{mg}$ protein, $p<$ 0.01 . However, vitamin $\mathrm{E}$ and TRAP did not differ between the two groups. Serum creatinine values and estimated GFR were similar in the two groups. Only in patients with microalbuminuria were significant linear correlations seen between AER and both oxidation $\left(\mathrm{HbA}_{1 \mathrm{c}} r=0.33, p<0.01\right.$; MDA $r=0.59, p<0.001$; pentosidine $r=0.48, p<0.001$; and AGE $r=0.44, p<0.001$ ) and antioxidation variables (vita$\min \mathrm{E} r=-0.55, p<0.001$; TRAP $r=-0.49, p<0.001$ ). Considering all variables together, multiple regression revealed a correlation between microalbuminuria and vitamin $\mathrm{E}, \mathrm{TRAP}, \mathrm{HbA}_{1 \mathrm{c}}$ and MDA, but not pentosidine or AGE.

Conclusions/interpretation Our data suggest that microalbuminuria in type 2 diabetic patients might be promoted by an insufficient counter-regulation of the antioxidant system in the event of increased glyco-oxidation/glycation.

Keywords Antioxidant status · Glyco-oxidation .

Microalbuminuria · Type 2 diabetes

\author{
Abbreviations \\ FPG Fasting plasma glucose \\ MDA Malonyldialdehyde \\ PCA Principal component analysis \\ ROS Reactive oxygen species \\ TRAP Total radical-trapping antioxidant parameter
}

\section{Introduction}

Several studies have shown that endothelial dysfunction in diabetes is closely associated with micro- and macro- 
angiopathy, retinopathy, nephropathy and atherosclerosis, i.e. the main determinants of morbidity and mortality in type 1 [1] and type 2 diabetic patients [2]. In both types of diabetes, microalbuminuria is related to increases in a number of markers of endothelial dysfunction [3, 4], which is why microalbuminuria is considered a marker of the risk of atherosclerosis and cardiovascular disease [5].

Various studies have shown that the initial damage leading to onset of microalbuminuria in diabetes occurs in glomerular endothelium. The most important aspect of this damage is disruption of the endothelial glycocalyx through the action of mediators, including reactive oxygen species (ROS), vascular endothelial growth factor and proinflammatory cytokines [6].

Hyperglycaemia results in the generation of ROS, increasing oxidative stress in affected tissues, which are damaged by the consequent activation of nuclear factor kappa B, along with AGE formation and activation of the protein kinase $\mathrm{C}$, sorbitol and hexosamine pathways [7-10]. Thus, in addition to increased ROS, diabetic patients also have a decline in antioxidant defence mechanisms, such as total plasma antioxidant capacity (or the total radical-trapping antioxidant parameter [TRAP]) and vitamin E [11].

In this setting, several studies have examined the possible relationship between microalbuminuria and AGE in type 1 diabetic patients [12-14]; a few have focused on type 2 diabetic patients [15-17]. In type 1 diabetes, serum AGE levels correlate with the stage of nephropathy [14], even suggesting a pathogenic role for them in the progression of early diabetic nephropathy [13]. Increases in skin collagen-linked pentosidine levels and AGE have also been correlated with AER [12]. In type 2 diabetes, renal function and various stages of proteinuria affect the urinary concentrations of pentosidine [15] and AGE [16]. However, measuring these variables in urine provides little additional information in patients with renal function impairment [16]. There are contrasting reports, moreover, on serum AGE levels and microalbuminuria in type 2 diabetic patients with normal renal function [17, 18].

Malonyldialdehyde (MDA) is frequently measured as an indicator of oxidative stress in vivo and is elevated in diabetic patients with macroangiopathy or microalbuminuria [19, 20].

To our knowledge, no studies have yet examined the possible relationship between glucose-induced oxidative stress, antioxidant status and microalbuminuria in type 2 diabetes, hence our interest in evaluating this topic.

\section{Methods}

Participants and protocol The study involved 99 consecutive type 2 diabetic patients (57 men, 42 women) who were regularly attending our outpatient clinic. On the day of the study, fasting blood samples were taken to determine fasting plasma glucose (FPG), $\mathrm{HbA}_{1 \mathrm{c}}, \mathrm{MDA}$, pentosidine, AGE, TRAP, vitamin E, creatinine, cholesterol and triacylglycerol. We also evaluated overnight AER. Three repeated overnight urine samples, taken over the previous 6 months, were considered to evaluate persistent microalbuminuria (defined as an AER $\geq 20 \mu \mathrm{g} / \mathrm{min}$ in at least two of three collections).

In the morning, after a $12 \mathrm{~h}$ overnight fast, blood was collected and immediately centrifuged at $1700 \mathrm{~g}$ and at $4^{\circ} \mathrm{C}$ for $20 \mathrm{~min}$. Glucose and AER were measured immediately, while the rest of the sample was frozen at $-80^{\circ} \mathrm{C}$ until use. All assays were performed within 3 months of sample collection. Experience has shown that no changes occur in these conditions.

Coronary heart disease, peripheral vascular disease (brain and lower extremities) and diabetic retinopathy were assessed from the hospital records; $90 \%$ of the patients were taking antihypertensive drugs.

Informed written consent was obtained from all participants taking part in the study.

Laboratory measurements Plasma glucose was determined using a glucose-oxidase method [21]. $\mathrm{HbA}_{1 \mathrm{c}}$ was measured by liquid chromatography [22] (Bio-Rad Laboratories, Milan, Italy). Total cholesterol, and LDL- and HDLcholesterol, were measured using enzymatic analytical chemistry (CHOD-PAP method; Roche, Milan, Italy) [23, 24], as was plasma triacylglycerol (GPO-PAP colorimetric enzyme test; Roche Diagnostic System) [25].

AER was measured using a standard nephelometric method with a specific albumin antibody (Dade Behring, Newark, DE, USA), with a coefficient of variation of $4.3 \%$ intra-assay and 4.4\% inter-assay [26]. The estimated GFR was calculated using the Cockcroft-Gault formula [27]. Pentosidine was measured by liquid chromatography [28] and AGE using an ELISA [29]. MDA was measured with a liquid chromatography method [30]. The TRAP was assessed according to Ghiselli et al. [31]. Vitamin E levels were measured by high-precision chromatography in a reverse-phase column using a diode array spectrophotometric detector, according to Laidman \& Hall [32].

Statistical analysis Data are expressed as mean \pm SD. For variables occurring as frequencies, statistical differences between the two groups of patients were determined using the $\chi^{2}$ test with Yates' correction [33]; Fisher's exact test was used when a frequency was less than five. Student's $t$ test was used for the multiple comparison of continuous variables. Differences were deemed statistically significant when $p<0.05$.

Least-square linear regression analysis was used to test any relationships between pairs of variables. Pearson's correlation coefficient $r$ was used to quantify the strength of the relationships. 
Multiple regression was used to further explore the linear relationships between the variables. The equation was in the form: $y=a+b_{1} \times x_{1}+b_{2} \times x_{2}+\ldots+b_{p} \times x_{p}$. Regression variables were estimated as well as the correlation coefficient $r$. ANOVA was used to assess the significance of the regression with significance accepted at $p<0.05$. As an alternative data evaluation method, stepwise backward regression analysis was also used on the variables.

A useful multivariate technique for reducing the dimensionality of the data set is principal component analysis (PCA), which may help identify new, meaningful underlying variables. The reduced set contains what are called 'principal factors', which are linear combinations of the original variables. The first principal component accounts for as much of the variability in the data as possible, with each successive component accounting for the remaining variability. BiPlot software (developed by I. Lipkovich and E.P. Smith [34]) was used, as Excel macros. The first three components were considered for data classification. A biplot graphic display was used to present the behaviour of variables in order to examine their correlation on the same chart. The length and the directions of vectors (rays) may be important in interpreting the data [35]. In this case, the most useful variable is the cosine of the eigenvectors that suggested correlations between different variables. When the angle between eigenvectors nears $0^{\circ}$, the variables are positively correlated, while the angle for negative correlations approaches $180^{\circ}$ and angles of $90^{\circ}$ indicate no correlation.

\section{Results}

The patients were divided into two groups, one with 62 patients who had persistent microalbuminuria (AER $\geq 20 \mu \mathrm{g} / \mathrm{min}$ ), the other with 37 individuals without microalbuminuria (AER $<20 \mu \mathrm{g} / \mathrm{min}$ ).

The patients' clinical characteristics and laboratory data are given in Table 1. No significant differences emerged between the two groups (type 2 diabetic patients with vs without microalbuminuria) for age, BMI, duration of diabetes,
Table 1 Clinical characteristics and laboratory data of the type 2 diabetic patients

Data are mean $\pm \mathrm{SD}$

Student's $t$ test was used for statistical evaluation of differences between continuous variables; the $\chi^{2}$ test with Yates' correction was used for frequency data

${ }^{\text {a }}$ Some patients were using a combination of more than one drug (up to three)

${ }^{*} p<0.05,{ }^{* *} p<0.01$ and ${ }^{\dagger} p<$ 0.005 for difference between patients with AER $<20$ vs AER $\geq 20 \mu \mathrm{g} / \mathrm{min}$

\begin{tabular}{|c|c|c|}
\hline \multirow[t]{2}{*}{ Variables } & \multicolumn{2}{|l|}{$\operatorname{AER}(\mu \mathrm{g} / \mathrm{min})$} \\
\hline & $<20$ & $\geq 20$ \\
\hline Participants, $n$ & 37 & 62 \\
\hline Age (years) & $63.6 \pm 5.4$ & $64.7 \pm 5.9$ \\
\hline Sex (men/women) & $20 / 17$ & $39 / 23$ \\
\hline Duration of diabetes (years) & $8.8 \pm 5.7$ & $8.2 \pm 5.7$ \\
\hline \multicolumn{3}{|l|}{ Arterial pressure $(\mathrm{mmHg})$} \\
\hline Diastolic & $84.7 \pm 6.7$ & $84.8 \pm 7.9$ \\
\hline Systolic & $147.5 \pm 17.5$ & $150.8 \pm 14.9$ \\
\hline \multicolumn{3}{|l|}{ Use of anti-hypertensive drugs } \\
\hline Renin-angiotensin system inhibitors $(n)$ & 27 & 50 \\
\hline Others $(n)^{\mathrm{a}}$ & 23 & 29 \\
\hline BMI & $28.9 \pm 5.1$ & $28.3 \pm 3.9$ \\
\hline FPG (mmol/l) & $8.19 \pm 1.93^{*}$ & $9.41 \pm 2.88$ \\
\hline $\mathrm{HbA}_{1 \mathrm{c}}(\%)$ & $7.39 \pm 1.03^{*}$ & $7.97 \pm 1.51$ \\
\hline Total serum cholesterol (mmol/1) & $5.69 \pm 0.90$ & $5.72 \pm 0.80$ \\
\hline LDL-cholesterol (mmol/1) & $3.59 \pm 0.86$ & $3.56 \pm 0.84$ \\
\hline HDL-cholesterol (mmol/l) & $1.35 \pm 0.33$ & $1.30 \pm 0.27$ \\
\hline Triacylglycerol (mmol/l) & $1.62 \pm 0.80$ & $1.74 \pm 0.84$ \\
\hline $\mathrm{AGE}(\mu \mathrm{g} / \mathrm{mg}$ protein $)$ & $10.6 \pm 3.8 * *$ & $13.2 \pm 4.8$ \\
\hline Pentosidine (pmol/ml) & $82.9 \pm 20.9 \dagger$ & $98.5 \pm 24.6$ \\
\hline $\operatorname{MDA}(\mu \mathrm{mol} / \mathrm{l})$ & $1.02 \pm 0.29^{*}$ & $1.18 \pm 0.35$ \\
\hline Vitamin $\mathrm{E}(\mu \mathrm{mol} / \mathrm{l})$ & $8.95 \pm 2.24$ & $8.23 \pm 2.11$ \\
\hline TRAP $(\mu \mathrm{mol} / \mathrm{l})$ & $807.5 \pm 87.4$ & $797.6 \pm 119.4$ \\
\hline Serum creatinine $(\mu \mathrm{mol} / \mathrm{l})$ & $77.8 \pm 6.2$ & $78.7 \pm 5.3$ \\
\hline Estimated GFR (ml/min) & $63.51 \pm 23.28$ & $70.57 \pm 24.48$ \\
\hline Coronary heart disease $(n)$ & 5 & 13 \\
\hline Current smokers $(n)$ & 8 & 15 \\
\hline
\end{tabular}


systolic and diastolic pressure, smoking habits, lipid profile or the use of renin-angiotensin system inhibitors. The two groups were also comparable with regard to coronary heart disease and none of the patients had retinopathy or peripheral vascular disease (cerebral and lower extremities).

Serum values for the following were significantly higher in patients with microalbuminuria than in those without microalbuminuria: FPG 9.41 \pm 2.88 vs $8.19 \pm 1.93 \mathrm{mmol} / 1, p<0.05$; $\mathrm{HbA}_{1 \mathrm{c}} 7.97 \pm 1.51$ vs $7.39 \pm 1.03 \%, p<0.05$; MDA $1.18 \pm 0.35$ vs $1.02 \pm 0.29 \mu \mathrm{mol} / 1, p<0.05$; AGE $13.2 \pm 4.8$ vs $10.6 \pm$ $3.8 \mu \mathrm{g} / \mathrm{mg}$ protein, $p<0.01$; and pentosidine $98.5 \pm 24.6 \mathrm{vs}$ $82.9 \pm 20.9 \mathrm{pmol} / \mathrm{ml}, p<0.005$. Vitamin E and TRAP did not differ between the two groups. Serum creatinine and estimated GFR values were similar in the two groups.

When we attempted to fit data pair-wise using linear regression analysis and considering diabetic patients with microalbuminuria, all glyco-oxidation/glycation variables, i.e. $\mathrm{HbA}_{1 \mathrm{c}}$ (Fig. 1a), MDA (Fig. 1b), pentosidine (Fig. 1c) and AGE (Fig. 1d), correlated directly with AER $(r=0.33$, $p<0.01 ; r=0.59, p<0.001 ; r=0.48, p<0.001$; and $r=0.44$, $p<0.001$; respectively), while the antioxidant variables, i.e. vitamin E (Fig. 1e) and TRAP (Fig. 1f), correlated inversely with AER $(r=-0.55, p<0.001$ and $r=-0.49, p<$ 0.001, respectively). Possible confounders (e.g. age, sex, diabetes duration, use of ACE inhibitors or angiotensin receptor blockers, serum creatinine, estimated GFR) were tested against AER and no significant correlation was found.

No such correlations between the above-mentioned variables and AER were found in patients without microalbuminuria.

Multiple linear regression was used in patients with AER $\geq 20 \mu \mathrm{g} / \mathrm{min}$ to identify any related predictors of microalbuminuria, evaluating the regression coefficients that represent the contributions of each independent variable to the predictive value of the dependent variable (AER). This model, which was applied to vitamin E and TRAP (as antioxidants) together with all the glyco-oxidation/glycation variables (considered as independent variables), as well as to AER as the dependent variable, showed that $\mathrm{HbA}_{1 \mathrm{c}}$ and MDA positively correlated, whereas vitamin E and TRAP correlated negatively (Table 2).

In another attempt to explain the links between the variables, we applied the multivariate PCA technique to the most relevant of the previously considered variables for patients with microalbuminuria. The resulting biplot graph suggests a close co-linear behaviour between MDA, pentosidine and AGE, which correlate inversely with vitamin $\mathrm{E}$ and TRAP. Microalbuminuria appeared to correlate with $\mathrm{HbA}_{1 \mathrm{c}}$ and MDA, as well as with pentosidine
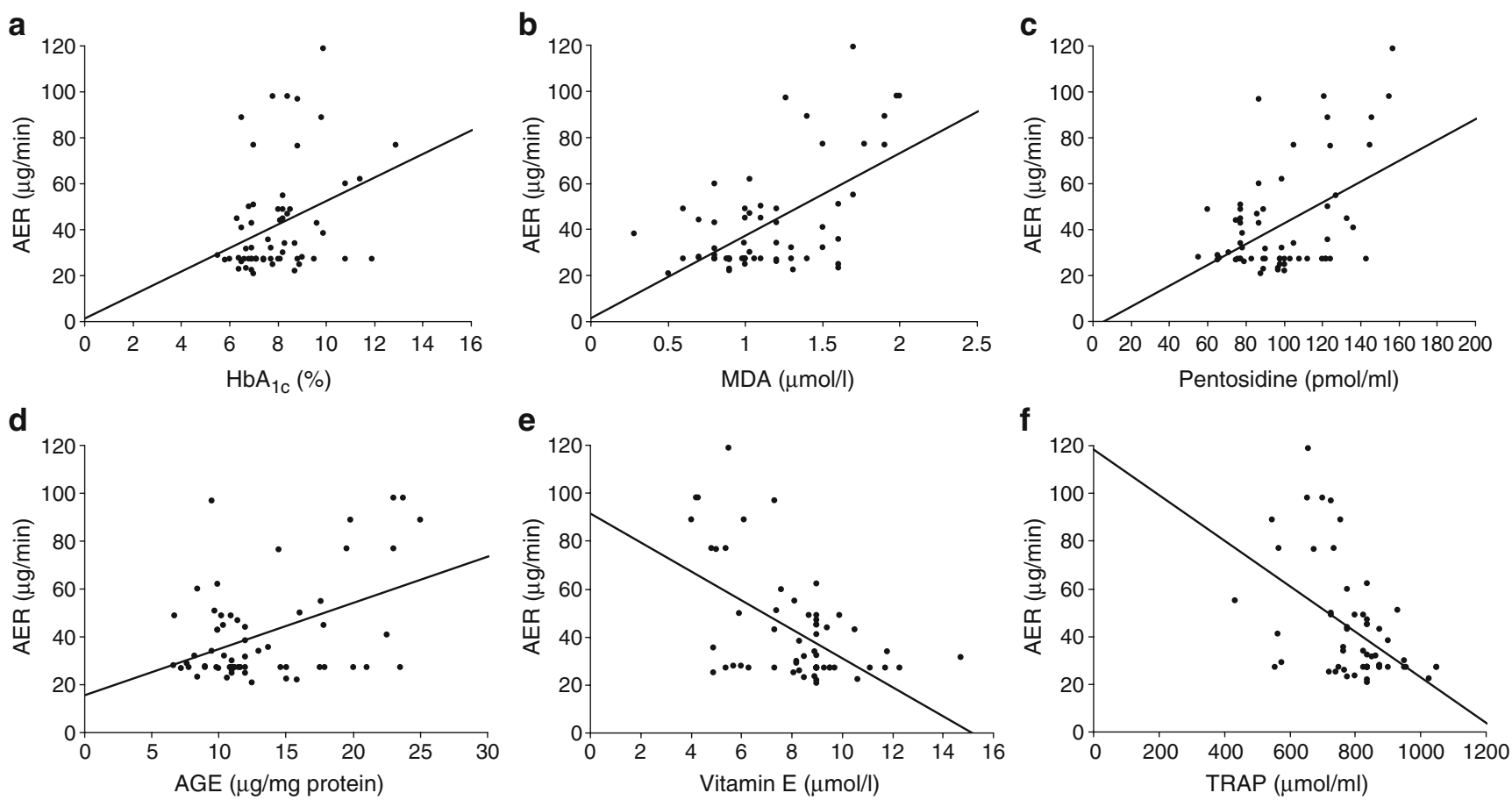

Fig. 1 Linear correlations between AER and $\mathrm{HbA}_{1 \mathrm{c}}$ (a, $y=5.1078 x+$ $1.4318, r=0.3325)$, MDA (b, $y=35.836 x+1.227, r=0.5913)$, pentosidine $(\mathbf{c}, y=0.4541 x-2.6303, r=0.4824)$, AGE $(\mathbf{d}, y=1.9317 x+$ $15.432, r=0.4432)$, vitamin $\mathrm{E}(\mathbf{e}, y=-6.0358 x+91.766, r=-0.5501)$ and TRAP (f, $y=-0.0954 x+118.17, r=-0.4922)$ in patients with microalbuminuria (AER $\geq 20 \mu \mathrm{g} / \mathrm{min}$ ). All the correlations were statistically significant $(n=62)$ 
Table 2 Variable estimates for multiple linear regression applied to glyco-oxidation and antioxidant variables obtained in patients with microalbuminuria

\begin{tabular}{lccccc}
\hline Term & Estimate & Standard error & $t$ ratio & $p$ value & \multicolumn{2}{c}{ Co-linearity statistics } \\
\cline { 4 - 6 } & & & & Tolerance \\
\hline Intercept & 49.879539 & 22.76511 & 2.19 & 0.0328 & \\
Pentosidine & -0.209446 & 0.159116 & -1.32 & 0.1936 (NS) & 0.243 \\
Vitamin E & -2.503302 & 1.025675 & -2.44 & 0.0180 & 0.739 \\
TRAP & -0.048918 & 0.018069 & -2.71 & 0.0091 & 0.739 \\
MDA & 21.508221 & 6.173037 & 3.48 & 0.0010 & 1.354 \\
AGE & 1.0280588 & 0.752153 & 1.37 & 0.1773 (NS) & 0.628 \\
HbA & 4.2312675 & 1.256709 & 3.37 & 0.0014 & 0.258 \\
\hline
\end{tabular}

Microalbuminuria was defined as AER $\geq 20 \mu \mathrm{g} / \mathrm{min}$

AER was the dependent variable; ANOVA revealed a statistically significant fit $(p<0.001)$

$r=0.7645, r^{2}=0.5845, r^{2}$ adjusted $=0.5384$

VIF, variance inflation factor

and AGE, whereas there was no apparent correlation between AGE or pentosidine and $\mathrm{HbA}_{1 \mathrm{c}}$ (Fig. 2).

\section{Discussion}

Oxidative stress (sustained in diabetes by hyperglycaemia and glyco-oxidation products such as $\mathrm{HbA}_{1 \mathrm{c}}$ and $\mathrm{AGE}$ ) and the absence of an appropriate compensatory response from the endogenous antioxidant network have been implicated in systemic endothelial dysfunction $[10,11]$, of which microalbuminuria is considered a marker [3, 36]. In this context, our patients with microalbuminuria had significantly higher FPG, $\mathrm{HbA}_{1 \mathrm{c}}, \mathrm{MDA}$, pentosidine and AGE levels than our normoalbuminuric patients, while no differ-

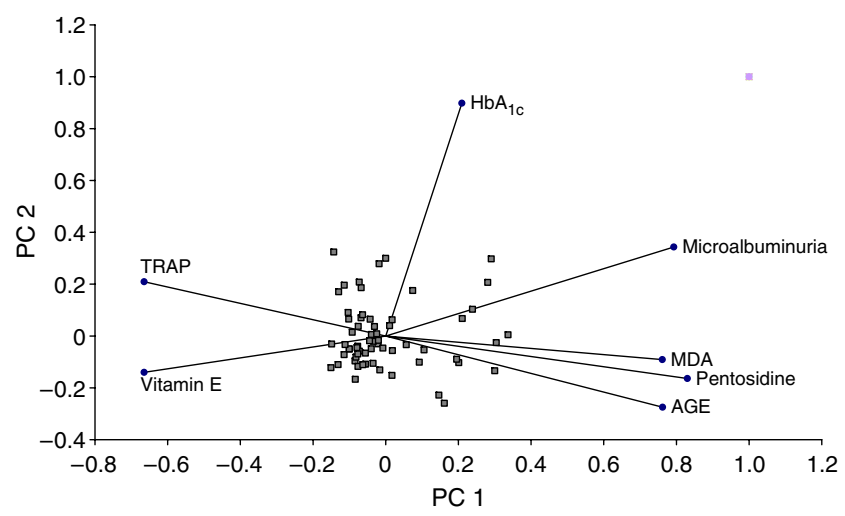

Fig. 2 Biplot of the first two principal components (PC 1 and PC 2) obtained by PCA (columns centred and standardised method, using BiPlot software [34]) conducted on seven of the most representative variables from patients with microalbuminuria (AER $\geq 20 \mu \mathrm{g} / \mathrm{min})(n=62)$ ences emerged with regard to antioxidants, such as vitamin $\mathrm{E}$ and TRAP. Only in microalbuminuric patients was a significant linear correlation seen between AER and both oxidation variables (which were positively correlated) and antioxidation variables (which were negatively correlated). When the variables were all considered together using multiple regression, vitamin $\mathrm{E}, \mathrm{TRAP}, \mathrm{HbA}_{1 \mathrm{c}}$ and $\mathrm{MDA}$, but not AGE and pentosidine, correlated with microalbuminuria. In our study, as in previous reports [13, 14, 20], patients with microalbuminuria had higher MDA, pentosidine and AGE serum levels than patients without microalbuminuria, even in conditions of normal renal function, and these factors may play a role in endothelial dysfunction. On the other hand, type 2 diabetic patients with macrovascular complications, and peripheral artery

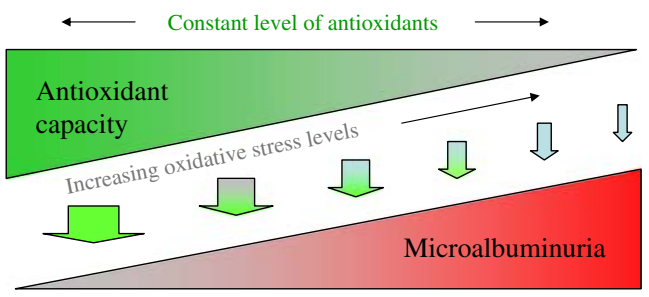

Fig. 3 Proposed scenario of factors involved in determining microalbuminuria in type 2 diabetic patients. The diagram shows the relationship between antioxidant capacity, seen in terms of the ratio of oxidative stress (represented by glyco-oxidation/glycation factors: pentosidine, AGE, MDA and $\mathrm{HbA}_{1 \mathrm{c}}$ ) to antioxidant levels (vitamin $\mathrm{E}$ and TRAP), and microalbuminuria. The area of the upper triangle is not a simple quantitative measure such as that for microalbuminuria presented in lower triangle, but is the result of interaction between oxidative stress and antioxidants. The antioxidant system could be a novel link between glyco-oxidation and development of renal microvascular damage in type 2 diabetes 
disease in particular, had high serum levels of MDA, pentosidine and AGE [37].

Aslan et al. found lower serum levels of antioxidants in type 2 diabetic patients with microalbuminuria, but provided no data on glyco-oxidation [38]. Other authors found that serum levels of antioxidants were much the same and tended to remain stable in various stages of non-metabolic kidney disease (changing only in patients with end-stage renal disease) despite a progressive increase in oxidative stress [39]. Our data from the PCA analysis suggest that microalbuminuria in type 2 diabetic patients might be promoted by an insufficient counter-regulation of the antioxidant system in the event of increased glycooxidation/glycation. These findings imply that it is not the amount of antioxidants, but rather the ratio of oxidative stress to antioxidant levels and the resulting antioxidant capacity that seem to be important (Fig. 3). The antioxidant system may therefore play a role in protecting against glycocalyx damage by glycaemia-induced oxidative stress. This study is the first to show the close relationship between antioxidant capacity and microalbuminuria in type 2 diabetic patients. A relationship had previously only been demonstrated in mice with experimental diabetes, where transgenic overexpression of superoxide dismutase attenuated renal injury, including increased AER [40].

In this light, antioxidant therapy might present an option for counteracting microalbuminuria. Several studies have been performed in type 1 and type 2 diabetic patients to establish the effects of vitamin $\mathrm{E}$ supplementation on their diabetic complications, but these studies are difficult to compare because natural vitamin $\mathrm{E}$ was used in some, while others used a synthetic compound; also different doses were given and the treatment periods differed. Clinical trials failed to demonstrate any beneficial effect of vitamin $\mathrm{E}$ on the development of microvascular complications (i.e. regression of microalbuminuria) in type 1 [41] or type 2 diabetic patients [42]. However, it has to be said that the patients in these studies had rather precarious metabolic control, both at baseline and at the end of the studies. Yokoyama et al. [43], in a small sample of microalbuminuric type 2 diabetic patients, found that a significant decrease of AER was induced by vitamin $\mathrm{E}$ supplementation only in patients with $\mathrm{HbA}_{1 \mathrm{c}}$ $<7 \%$, with AER increasing in patients with $\mathrm{HbA}_{1 \mathrm{c}}>7 \%$.

It may be that the antioxidative system works better in conditions of good metabolic control, in which case antioxidant supplementation could be useful in counteracting hyperglycaemia-induced oxidative stress and consequently also microalbuminuria.

A major weakness of the present study is the small study population, which may affect the feasibility of extending these results to the general population of type 2 diabetic patients with microalbuminuria. A study characterised by a randomised crossover placebo control is needed to verify our results.
Duality of interest The authors declare that there is no duality of interest associated with this manuscript.

\section{References}

1. Deckert T, Yokoyama H, Mathiesen E et al (1996) Cohort study of predictive value of urinary albumin excretion for atherosclerotic vascular disease in patients with insulin-dependent diabetes. BMJ 1312:871-874

2. Gall MA, Borch-Johnsen K, Hougaard P, Nielsen FS, Parving HH (1995) Albuminuria and poor glycemic control predict mortality in non-insulin-dependent diabetes mellitus. Diabetes 44:1301-1309

3. Stehouwer CDA (1997) von Willebrand factor, dysfunction of the vascular endothelium, and the development of renal and vascular complications in diabetes. In: Mogensen CE (ed) The kidney and hypertension in diabetes mellitus. Kluwer, Boston, pp 155-163

4. Schmidt AM, Crandall J, Hori O, Cao R, Lakatta E (1996) Elevated plasma levels of vascular cell adhesion molecule-1 (VCAM-1) in diabetic patients with microalbuminuria: a marker of vascular dysfunction and progressive vascular disease. $\mathrm{Br} \mathrm{J}$ Haematol 92:747-750

5. Naidoo DP (2002) The link between microalbuminuria, endothelial dysfunction and cardiovascular disease in diabetes. Cardiovasc J S Afr 13:194-199

6. Satchell SC, Tooke JE (2008) What is the mechanism of microalbuminuria in diabetes: a role for the glomerular endothelium? Diabetologia 51:714-725

7. Brownlee M (2005) The pathophysiology of diabetic complications: a unifying mechanism. Diabetes 54:1615-1625

8. Nishikawa T, Edelstein D, Du XL et al (2000) Normalizing mitochondrial superoxide production blocks three pathways of hyperglycaemic damage. Nature 404:787-790

9. Lee TS, MacGregor LC, Fluharty SJ, King GL (1989) Differential regulation of protein kinase $\mathrm{C}$ and $(\mathrm{Na}, \mathrm{K})$-adenosine triphosphatase activities by elevated glucose levels in retinal capillary endothelial cells. J Clin Invest 83:90-94

10. Evans JL, Goldfine ID, Maddux BA, Grodsky GM (2002) Oxidative stress and stress-activated signaling pathways: a unifying hypothesis of type 2 diabetes. Endocr Rev 23:599-622

11. Maxwell SR, Thomason H, Sandler D et al (1997) Antioxidant status in patients with uncomplicated insulin-dependent and noninsulin-dependent diabetes mellitus. Eur J Clin Invest 271:484-490

12. Beisswenger PJ, Moore LL, Brinck-Johnsen T, Curphey TJ (1993) Increased collagen-linked pentosidine levels and advanced glycosylation end products in early diabetic nephropathy. J Clin Invest 92:212-217

13. Berg TJ, Bangstad HJ, Torjesen PA, Osterby R, Bucala R, Hanssen KF (1997) Advanced glycation end products in serum predict changes in the kidney morphology of patients with insulindependent diabetes mellitus. Metabolism 46:661-665

14. Miura J, Yamagishi S, Uchigata Y et al (2003) Serum levels of $N$ carboxymethyllysine advanced glycation endproducts are correlated to severity of microvascular complications in patients with type 1 diabetes. J Diabetes Complications 17:16-21

15. Aso Y, Takanashi K, Sekine K et al (2004) Dissociation between urinary pyrraline and pentosidine concentrations in diabetic patients with advanced nephropathy. J Lab Clin Med 144:92-99

16. Turk N, Mornar A, Mrzljak V, Turk Z (2003) Urinary excretion of advanced glycation end products in patients with type 2 diabetes and various stages of proteinuria. Diabetes Metab 30:187-192

17. Wautier MP, Massin P, Guillausseau PJ et al (2003) N(carboxymethyl) lysine as a biomarker for microvascular complications in type 2 diabetic patients. Diabetes Metab 29:44-52 
18. Hirata K, Kubo K (2004) Relationship between blood levels of $N$ carboxymethyl-lysine and pentosidine and the severity of microangiopathy in type 2 diabetes. Endocr J 51:537-544

19. Gallou G, Ruelland A, Legras B, Maugendre D, Allannic H, Cloarec L (1993) Plasma malondialdehyde in type 1 and type 2 diabetic patients. Clin Chim Acta 214:227-234

20. Ozdemir G, Ozden M, Maral H, Kuskay S, Cetinalp P, Tarkun I (2005) Malondialdehyde, glutathione, glutathione peroxidase and homocysteine levels in type 2 diabetic patients with and without microalbuminuria. Ann Clin Biochem 42:99-104

21. Huggett AST, Nixon DA (1957) Use of glucose oxidase peroxidase and $O$-dianisine in the determination of blood and urine glucose. Lancet 2:368-370

22. Jaynes PK, Willis MC, Chon PP (1993) Evaluation of minicolumn chromatographic procedure for the measurement of $\mathrm{HbA} 1 \mathrm{c}$. Clin Biochem 39:2162-2165

23. Allain CC, Poon LS, Chan CS, Richmond W, Fu PC (1974) Enzymatic determination of total serum cholesterol. Clin Chem 20:470-475

24. Lipid Research Clinics Program (1982) Lipid and lipoprotein analysis. In: Hainline A, Karon J, Lippel K (eds) Manual of laboratory operations. Washington DC, pp 63-77

25. Fossati P, Prencipe L (1982) Serum triglycerides determined colorimetrically with an enzyme that produces hydrogen peroxide. Clin Chem 28:2077-2080

26. Rowe DJ, Dawnay A, Watts GF (1990) Microalbuminuria in diabetes mellitus: review and recommendations for the measurement of albumin in urine. Ann Clin Biochem 27:297-312

27. Cockcroft DW, Gault MH (1976) Prediction of creatinine clearance from serum creatinine Nephron 16:31-41

28. Odetti P, Fogarthy J, Sell D, Monnier VM (1992) Chromatographic quantitation of plasma and erythrocyte pentosidine in diabetic and uremic subjects. Diabetes 41:153-159

29. Makita Z, Vlassara H, Cerami A, Bucala R (1992) Immunochemical detection of advanced glycosylation end products in vivo. $\mathrm{J}$ Biol Chem 267:5133-5138

30. Hendricks T, Assmann RF (1998) On the fluorimetric assay of circulating lipoperoxides. Clin Chim Acta 174:263-270

31. Ghiselli A, Serafini M, Maiani G, Azzini E, Ferro-Luzzi A (1995) A fluorescence-based method for measuring total plasma antioxidant capacity. Free Radic Biol Med 18:29-36
32. Laidman DL, Hall GS (1971) Adsorption column chromatography of tocopherols. In: McCormick DB, Wright LD (eds) Methods in enzymology, part C: vitamins and coenzymes, vol 18. Academic Press, New York, pp 349-356

33. Armitage P (1971) Statistical methods in medical research. Blackwell, Oxford

34. Lipkovich I, Smith EP (2002) Biplot and singular value decomposition macros for Excel. J Statistical Software 7:1-15

35. Aitchinson J, Greenacre M (2002) Biplots of compositional data. Appl Stat 51:375-392

36. Dinneen SF, Gerstein HC (1997) The association of microalbuminuria and mortality in non-insulin-dependent diabetes mellitus. Arch Int Med 157:1413-1418

37. Lapolla A, Piarulli F, Sartore G et al (2007) Advanced glycation end products and antioxidant status in type 2 diabetic patients with and without peripheral artery disease. Diabetes Care 30:670-676

38. Aslan M, Sabuncu T, Kocyigit A, Celik H, Selek S (2007) Relationship between total oxidant status and severity of diabetic nephropathy in type 2 diabetic patients. Nutr Metab Cardiovasc Dis $17: 734-740$

39. Karamouzis I, Sarafidis PA, Karamouzis M et al (2008) Increase in oxidative stress but not in antioxidant capacity with advancing stages of chronic kidney disease. Am J Nephrol 28:397-404

40. DeRubertis FR, Craven PA, Melhem MF, Salah EM (2004) Attenuation of renal injury in $\mathrm{db} / \mathrm{db}$ mice overexpressing superoxide dismutase: evidence for reduced superoxide-nitric oxide interaction. Diabetes 53:762-768

41. Giannini C, Lombardo F, Currò F et al (2007) Effects of high-dose vitamin $\mathrm{E}$ supplementation on oxidative stress and microalbuminuria in young adult patients with childhood onset type 1 diabetes mellitus. Diabetes Metab Res Rev 23:539-546

42. Lonn E, Yusuf S, Hoogwerf B, HOPE Study; MICRO-HOPE Study et al (2002) Effects of vitamin E on cardiovascular and microvascular outcomes in high-risk patients with diabetes: results of the HOPE study and MICRO-HOPE substudy. Diabetes Care 25:1919-1927

43. Yokoyama M, Torita M, Yoshizawa M, Usuda R (2001) Indication of vitamin $\mathrm{E}$ on microalbuminuria in patients with incipient diabetic nephropathy. Diabetes Metab 27:611-612 